Rev. Bras. Saúde Prod. Anim., Salvador, v.16, n.3, p.558-570 jul./set.., 2015 http://www.rbspa.ufba.br

\title{
Desempenho, consumo de nutrientes e comportamento ingestivo de cordeiros alimentados com diferentes teores de torta de soja em substituição ao farelo de soja
}

\author{
Performance, nutrient intake and ingestive behavior of lambs fed with different levels of \\ soybean cake in replacement of soybean meal
}

GRANDIS, Fernando Augusto ${ }^{1 *}$; RIBEIRO, Edson Luis de Azambuja ${ }^{2}$; MIZUBUTI, Ivone Yurika'; SILVA, Leandro das Dores Ferreira $\mathrm{da}^{2}$; BUMBIERIS JUNIOR, Valter Harry $^{2}$; PRADO, Odimári Pricila Pires do ${ }^{2}$; CONSTANTINO, Camila ${ }^{1}$; FERNANDES JUNIOR, Francisco ${ }^{1}$; MANGILLI, Lívia Galiano ${ }^{1}$; PEREIRA, Elzânia Sales ${ }^{3}$

\footnotetext{
${ }^{1}$ Universidade Estadual de Londrina, Programa de Pós-Graduação em Ciência Animal, Londrina, Paraná, Brasil.

${ }^{2}$ Universidade Estadual de Londrina, Departamento de Zootecnia, Londrina, Paraná, Brasil.

${ }^{3}$ Universidade Federal do Ceará, Departamento de Zootecnia, Fortaleza, Ceará, Brasil.

*Endereço para correspondência: fernando_grandis@yahoo.com.br
}

\section{RESUMO}

O objetivo deste trabalho foi avaliar o efeito da substituição do farelo de soja pela torta de soja em dietas para cordeiros Santa Inês confinados, avaliando o desempenho, consumo de nutrientes, comportamento ingestivo e medidas biométricas. Foram utilizados 30 cordeiros machos não castrados, com 23,63 $\pm 2,44 \mathrm{~kg}$ de peso corporal, distribuídos de maneira inteiramente casualizada em cinco tratamentos, sendo assim 6 repetições por tratamento, os quais foram os teores de substituição do farelo de soja pela torta de soja de $0 ; 25 ; 50 ; 75$ e $100 \%$. O comportamento ingestivo foi avaliado através de observações pontuais a cada 10 minutos durante 24 horas. Não foi observado efeito significativo sobre os parâmetros de desempenho, consumo de matéria seca e de comportamento ingestivo. $\mathrm{O}$ ganho de peso médio diário foi de $312,73 \mathrm{~g}$, o consumo médio de matéria seca foi de $1,44 \mathrm{~kg} /$ dia. A inclusão da torta de soja levou a um aumento linear no consumo de extrato etéreo em gramas/dia, em porcentagem do peso corporal e em porcentagem do peso metabólico. Foi observado efeito cúbico sobre parâmetros de consumo de fibra em detergente ácido. Os tempos de ruminação, alimentação e ócio foram de 425,85; 194,50 e $789,29 \mathrm{~min} /$ dia, respectivamente. Em relação às medidas biométricas, não foi encontrado efeito da substituição do farelo de soja pela torta de soja. A torta de soja pode ser utilizada na substituição do farelo de soja, devendo-se atentar ao teor de extrato etéreo residual presente neste coproduto da indústria do biodiesel.

Palavras-chave: biodiesel, confinamento, coproduto, ovinos

\section{SUMMARY}

The objective of this study was to evaluate the effect of replacing soybean meal by soybean cake in diets for feedlot Santa Ines lambs, evaluating performance, nutrient intake, ingestive behavior and biometric measures. Thirty intact males were used, weighing $23.63 \pm$ $2.44 \mathrm{~kg}$, distributed randomly in five treatments, with 6 animals each, with the treatments being the levels of substitution of soybean meal for soybean cake, by $0 ; 25 ; 50 ; 75$ and $100 \%$. The ingestive behavior was assessed by visual observations every 10 minutes, during 24 hours. No significant effects were found on the parameters of performance, DM intake, and ingestive behavior. The average daily weight gain was $312,73 \mathrm{~g}$, and the average dry matter intake was $1,44 \mathrm{~kg} /$ day. The inclusion of soybean cake led to a significant linear increase in ether extract intake in grams/day, in percentage of body weight and in percentage of metabolic weight. Cubic effects were observed in the parameters of acid detergent fiber intake. The rumination, feed intake and idleness time observed were 425,85; 194,50 e 789,29 
min/day, respectively. Regarding biometric measurements, there was no significant effect of replacing soybean meal with soybean cake. The soybean cake can be used in replacement of soybean meal, but is important to pay attention on the content of residual lipids present in this byproduct of the biodiesel industry.

Keywords: biodiesel, byproduct, feedlot, sheep

\section{INTRODUÇÃO}

Apesar do consumo da carne ovina estar aumentando no Brasil, e de seu grande potencial para competir com os maiores produtores, a baixa qualidade do produto ofertado e a estacionalidade da oferta são os principais problemas que dificultam a maior expansão da atividade (SIQUEIRA et al., 2002; MADRUGA et al., 2005).

Assim a terminação de cordeiros em confinamento pode trazer benefícios, como redução da idade de abate, padronização das carcaças e melhor utilização do potencial produtivo do animal (PAIM et al., 2011). Entretanto, no geral ocorre aumento significativo nos gastos com alimentação, podendo inviabilizar a atividade (BARROS et al., 2009).

$\mathrm{O}$ uso de coprodutos da indústria do biodiesel no confinamento pode ser uma alternativa interessante para redução dos custos, além de também possibilitar a diminuição de potenciais problemas ambientais, causados por sua deposição no ambiente (MOTA \& PESTANA, 2011).

Os biocombustíveis vêm sendo cada vez mais empregados no Brasil, e no processo de extração do óleo, é gerada grande quantidade de material residual, os quais podem apresentar potencial de uso na alimentação de ruminantes (ABDALLA et al., 2008; SANTOS et al., 2012).
A soja é a oleaginosa mais usada na indústria do biodiesel, correspondendo a cerca de $74 \%$ das matérias-primas empregadas (BRASIL, 2014). No geral, é empregado o método químico para a extração do óleo, utilizando o hexano, em alta temperatura, em que se obtém o óleo e o farelo de soja, o qual e é caracterizado por possuir baixo teor de extrato etéreo.

Como alternativa no método de extração do óleo, pode-se realizar a prensagem a frio do grão de soja. Apesar deste processo extrativo não ser tão eficiente em larga escala, pode ser uma alternativa economicamente interessante para minifúndios, visto que apenas uma prensa simples é requerida no processamento dos grãos. Adotando tal método, o pequeno produtor teria a possibilidade de realizar o plantio e a prensagem dos grãos de soja em sua propriedade para o fornecimento aos animais, sem a exigência de instalações específicas e com baixo risco à sua segurança (SANTOS et al., 2014). O maior teor de extrato etéreo residual presente nas tortas também pode ser benéfico aos animais, principalmente em climas mais quentes (PALMQUIST \& MATTOS, 2011).

Objetivou-se avaliar a substituição do farelo de soja por torta de soja sobre o desempenho, consumo de nutrientes e comportamento ingestivo de cordeiros Santa Inês terminados em confinamento.

\section{MATERIAL E MÉTODOS}

O experimento foi realizado na Fazenda Escola e Departamento de Zootecnia da Universidade Estadual de Londrina. O experimento foi conduzido de acordo com as normas éticas e aprovado pela Comissão de ética no uso de animais 
Rev. Bras. Saúde Prod. Anim., Salvador, v.16, n.3, p.558-570 jul./set.., 2015 http://www.rbspa.ufba.br ISSN 15199940

(CEUA-UEL), ofício circular $\mathrm{n}^{\mathrm{o}}$ 123/2010.

Foram utilizados 30 animais da raça Santa Inês, machos não castrados, que permaneceram confinados em período de avaliação durante os meses de setembro a outubro de 2012, durante 47 dias, após passarem por 14 dias de adaptação às condições experimentais, totalizando 61 dias de confinamento. Após a adaptação, os animais tinham aproximadamente 80 dias de idade e peso de $23,63 \pm 2,44 \mathrm{~kg}$ (peso inicial). No início do experimento, além de pesados, os animais foram identificados, vacinados contra clostridioses, vermifugados, e distribuídos aleatoriamente em duplas, em baias de $2 \mathrm{~m}^{2}$, em aprisco coberto, com piso ripado, providas de comedouro e bebedouro.

O delineamento empregado foi inteiramente casualizado, com os animais sendo as repetições, e cada uma das dietas sendo fornecidas a seis animais. As dietas foram: sem torta de soja, com 25; 50; 75 e $100 \%$ de substituição do farelo de soja por torta de soja. Durante o período experimental, devido a uma pneumonia, um cordeiro do tratamento de $25 \%$ precisou ser medicado e removido do experimento.

As rações foram pesadas e fornecidas duas vezes ao dia (7h00 e 16h00), na forma total (volumoso e concentrado). As sobras foram pesadas diariamente e a quantidade de ração a ser ofertada era ajustada de acordo com o consumo do dia anterior, permitindo sobras de $20 \%$ do total da matéria natural oferecida na ração.

As rações foram formuladas após a análise bromatológica dos ingredientes utilizados nas rações experimentais (Tabela 1), realizadas no Laboratório de Nutrição Animal, pertencente à Universidade Estadual de Londrina, segundo a metodologia de Silva \& Queiroz (2002) para matéria seca (MS), matéria mineral $(\mathrm{MM})$, proteína bruta (PB) e extrato etéreo (EE). Para fibra em detergente neutro (FDN) e fibra em detergente ácido (FDA), foi utilizado o método de Detmann et al. (2012). Os nutrientes digestíveis totais (NDT) foi estimado segundo Kearl (1982).

Tabela 1. Composição químico-bromatológica dos ingredientes das rações experimentais

\begin{tabular}{lccccccc}
\hline \multirow{2}{*}{ Ingrediente } & \multicolumn{7}{c}{ Componente nutricional (g/kg MS) } \\
\cline { 2 - 7 } & MS $^{1}$ & MM & PB & EE & FDN & FDA & NDT \\
\hline Silagem Sorgo & 320,36 & 61,43 & 65,17 & 18,59 & 622,95 & 349,27 & 588,26 \\
Milho tritur. & 886,63 & 9,74 & 95,59 & 37,29 & 149,42 & 19,73 & 828,91 \\
Farelo de Soja & 905,34 & 58,35 & 488,71 & 10,68 & 240,12 & 63,43 & 818,63 \\
Torta de Soja & 894,19 & 52,02 & 474,01 & 74,13 & 224,40 & 58,74 & 886,52 \\
Calc. calcítico & 990,00 & - & - & - & - & - & - \\
Mist. mineral $^{2}$ & 990,00 & - & - & - & - & - & - \\
\hline
\end{tabular}

${ }^{\mathrm{I}} \mathrm{g} / \mathrm{kg} \mathrm{MN}$; ${ }^{2}$ Mistura Mineral: Cálcio 128,00g; Enxofre 10,00g; Fósforo 60,00g; Magnésio 6.000,00mg; Sódio 152,00mg; Cobalto 50,00mg; Ferro 1.400,00mg; Iodo 74,00mg; Manganês 1.800,00mg; Selênio 15,00mg; Zinco $2.730 \mathrm{mg}$; Flúor 600,00mg.

As rações eram isonitrogenadas, constituídas de silagem de sorgo e concentrado composto por farelo de soja (e/ou torta de soja), milho triturado, calcário calcítico e mistura mineral comercial, formuladas para atender as exigências nutricionais segundo o NRC (1985; 2007) (Tabela 2), para cordeiros 
Rev. Bras. Saúde Prod. Anim., Salvador, v.16, n.3, p.558-570 jul./set.., 2015 http://www.rbspa.ufba.br

de maturação tardia, com $20 \mathrm{~kg}$ de peso corporal, com ganho de peso diário de $250 \mathrm{~g}$. A relação volumoso: concentrado (V:C) empregada foi de 35:65.

Diariamente foram realizadas pesagens da ração ofertada e das sobras de cada baia para a estimativa de consumo de matéria seca (CMS), calculando a média da quantidade fornecida e das sobras e dividindo pelo número de dias de avaliação no confinamento (47). Foram realizadas coletas semanais da ração fornecida e das sobras, para a determinação de MS, PB, EE, FDN, FDA, segundo Silva \& Queiroz (2002) e Detmann et al. (2012).

Tabela 2. Proporção dos ingredientes e composição nutricional das rações experimentais (g/ kg MS)

\begin{tabular}{lccccc}
\hline \multirow{2}{*}{ Ingredientes } & \multicolumn{5}{c}{ Teores de torta de soja (\%) } \\
\cline { 2 - 6 } & 0 & 25 & 50 & 75 & 100 \\
\hline Silagem Sorgo & 350,00 & 350,00 & 350,00 & 350,00 & 350,00 \\
Milho triturado & 392,40 & 392,40 & 392,40 & 392,40 & 392,40 \\
Farelo de Soja & 242,60 & 181,95 & 121,30 & 60,65 & 0,00 \\
Torta de Soja & 0,00 & 60,65 & 121,30 & 181,95 & 242,60 \\
Calcário calcítico & 10,00 & 10,00 & 10,00 & 10,00 & 10,00 \\
Mistura Mineral & 5,00 & 5,00 & 5,00 & 5,00 & 5,00 \\
\hline Composição nutricional & & & & & \\
\hline Matéria seca (g/kg MN) & 679,67 & 679,00 & 678,32 & 677,65 & 676,97 \\
Matéria mineral (g/kg MS) & 39,48 & 39,09 & 38,71 & 38,32 & 37,94 \\
Proteína bruta (g/kg MS) & 178,88 & 177,99 & 177,09 & 176,20 & 175,31 \\
Extrato etéreo (g/kg MS) & 23,73 & 27,58 & 31,43 & 35,28 & 39,12 \\
Fibra detergente neutro (g/kg MS) & 334,92 & 333,97 & 333,01 & 332,06 & 331,10 \\
Fibra detergente ácido (g/kg MS) & 145,38 & 145,09 & 144,81 & 144,52 & 144,24 \\
NDT(g/kg MS) & 729,75 & 733,87 & 737,99 & 742,11 & 746,23 \\
\hline
\end{tabular}

${ }^{1}$ Nutrientes Digestíveis Totais, equações propostas por Kearl (1982).

Essas amostras foram encaminhadas para uma estufa de circulação forçada a $55 \pm$ $5^{\circ} \mathrm{C}$, durante 72 horas. Após a présecagem, as amostras foram trituradas em moinho de facas com peneira de 20 mesh, momento em que foram preparadas as amostras compostas de acordo com a dieta. Em seguida, identificou-se e acondicionou-se essas amostras para posterior análise.

Com os valores de CMS estimados por baia, para obtenção dos valores para cada animal, dividiu-se o consumo de matéria seca por baia pelo número de animais em cada baia.

Baseado nos valores de consumo em matéria seca e a matéria seca das sobras, multiplicou-se a composição química do fornecido pela sua quantidade ingerida $\mathrm{e}$ comparou-se com a quantidade de sobras multiplicada pela sua composição química, para obtenção do consumo dos componentes nutricionais (PB, EE, FDN, FDA, NDT), os quais foram expressos em gramas/animal/dia, em porcentagem do peso corporal $(\% \mathrm{PC})$ e em grama por quilograma de peso metabólico $\left(\mathrm{g} / \mathrm{kg} \mathrm{PC}^{0,75}\right)$.

Para o registro do comportamento ingestivo, no quadragésimo dia do período de avaliação, os cordeiros foram observados em intervalos de 10 minutos, durante 24 horas, para a determinação dos tempos despendidos na ingestão de sólidos, ruminação e ócio (CARVALHO et al., 2007).

Ao final do período experimental, realizou-se a pesagem dos animais, 
Rev. Bras. Saúde Prod. Anim., Salvador, v.16, n.3, p.558-570 jul./set.., 2015 http://www.rbspa.ufba.br

precedida de um período de 16 horas de jejum de sólidos, para a obtenção do peso corporal final, do ganho médio diário de peso e conversão alimentar. Determinou-se o escore de condição corporal, de acordo com metodologia de Osório \& Osório (2005).

Também foram aferidas as seguintes medidas morfométricas pré-abate: comprimento corporal, comprimento da perna, perímetro da perna, altura do dorso, altura da garupa, perímetro torácico, largura de garupa e largura de peito, utilizando fita métrica e paquímetro de madeira. Para tais determinações, os animais foram mantidos em estação forçada, ou seja, membros anteriores e posteriores perpendiculares a um piso plano cimentado (YÁÑEZ et al., 2004). Os dados obtidos foram submetidos a análise de variância e regressão polinomial, no caso de significância ao nível de $5 \%$, utilizando o pacote estatístico SAS versão 8.2 (SAS, 2001).

\section{RESULTADOS E DISCUSSÃO}

Não foi observado efeito $(\mathrm{P}>0,05)$ da substituição do farelo de soja pela torta de soja em nenhum dos parâmetros de desempenho avaliados (Tabela 3 ).

Tabela 3. Desempenho de cordeiros confinados alimentados com dietas contendo diferentes teores de torta de soja em substituição ao farelo de soja

\begin{tabular}{|c|c|c|c|c|c|c|c|}
\hline \multirow{2}{*}{ Variável } & \multicolumn{5}{|c|}{ Teores de torta de soja (\%) } & \multirow{2}{*}{$\mathrm{R}$} & \multirow{2}{*}{$\begin{array}{l}\text { CV } \\
(\%)\end{array}$} \\
\hline & 0 & 25 & 50 & 75 & 100 & & \\
\hline Peso inicial (kg) & 23,37 & 24,38 & 24,07 & 23,42 & 23,78 & $\tilde{y}=23,78$ & 13,47 \\
\hline Peso final $(\mathrm{kg})$ & 39,12 & 38,90 & 39,38 & 37,73 & 37,35 & $\tilde{y}=38,48$ & 9,33 \\
\hline GPD $(g)$ & 335,33 & 309,00 & 326,00 & 304,67 & 288,67 & $\tilde{y}=312,73$ & 14,93 \\
\hline CMS (kg/dia) & 1,50 & 1,44 & 1,55 & 1,41 & 1,30 & $\tilde{y}=1,44$ & 12,47 \\
\hline CMS (kg/100 kg PC) & 4,80 & 4,59 & 4,88 & 4,62 & 4,26 & $\tilde{y}=4,63$ & 9,41 \\
\hline CMS (kg/PC $\left.{ }^{0,75}\right)$ & 0,11 & 0,11 & 0,12 & 0,11 & 0,10 & $\tilde{y}=0,11$ & 9,17 \\
\hline $\mathrm{CA}$ & 4,54 & 4,72 & 4,81 & 4,69 & 4,60 & $\tilde{y}=4,67$ & 17,83 \\
\hline
\end{tabular}

$\mathrm{GPD}=$ ganho de peso diário, $\mathrm{CMS}=$ consumo de matéria seca, $\mathrm{CV}=$ coeficiente de variação, $\mathrm{R}=$ regressão, $\mathrm{PC}=$ peso corporal, $\mathrm{PC}^{0,75}=$ peso metabólico.

Segundo Amaral et al. (2011), ovinos Santa Inês possuem capacidade ingestiva inferior às raças especializadas para carne. Portanto, a associação de uma provável menor exigência de mantença encontrada em animais Santa Inês aliada com o alto teor de concentrado na ração utilizada neste estudo, pode ter contribuído com este resultado de ganho de peso diário (GPD), superior à formulação empregada, baseada no NRC (1985; 2007).

As semelhanças entre os GPD proporcionados pelas diferentes dietas experimentais é muito interessante, pois significa que ao substituir uma das fontes proteicas mais usadas na alimentação animal, o farelo de soja, por uma fonte similar, de mais fácil obtenção a nível de campo, o desempenho dos animais foi mantido satisfatório.

Zundt et al. (2006) encontraram ganhos de peso de 190g/dia, utilizando uma dieta à base de feno de tifton, milho e soja, contendo $75 \%$ de NDT e $20 \%$ de $\mathrm{PB}$, para cordeiros Santa Inês confinados, com relação V:C de $30: 70$. Estes valores foram muito próximos aos 
Rev. Bras. Saúde Prod. Anim., Salvador, v.16, n.3, p.558-570 jul./set.., 2015 http://www.rbspa.ufba.br ISSN 15199940

valores empregados no presente trabalho. Entretanto, no estudo de Zundt et al. (2006), a conversão alimentar média obtida pelos autores também foi pior que a do presente trabalho. Observa-se que mesmo quando se compara dietas com valores nutricionais próximos, as características dos volumosos podem exercer importante influência sobre os resultados.

Não foram observadas diferenças significativas nos parâmetros de consumo de MS $(\mathrm{P}>0,05)$ entre as dietas experimentais. Moura et al. (2015), em estudo de digestibilidade in vivo com ovinos em gaiolas metabólicas, utilizando a mesma torta de soja empregada no presente estudo, e os mesmos níveis de substituição do farelo de soja pela torta de soja também não encontraram diferenças no consumo de matéria seca entre as diferentes dietas. Foi constatado pelos autores que a substituição do farelo de soja pela torta de soja em até $100 \%$ não afeta negativamente a digestibilidade da MS, proporcionando CMS similar entre as diferentes dietas experimentais.

Em relação à conversão alimentar (CA), inúmeros fatores podem a afetar, como a natureza e composição da dieta, idade, grupo genético, sistema produtivo, entre outros. Como essas fontes de variação foram similares entre os animais utilizados, e o CMS e o GPD foram semelhantes entre todos animais, a conversão alimentar também não foi influenciada $(\mathrm{P}>0,05)$ pela dieta, apresentando valor médio de 4,67.

Ribeiro et al. (2011) encontraram valor de conversão alimentar médio de 4,26 para cordeiros Santa Inês confinados, utilizando $47 \%$ de silagem de sorgo e $53 \%$ de ração concentrada à base de milho e soja. Estes valores de conversão foram próximos aos obtidos no presente estudo (4,67), apesar da maior porcentagem de volumoso empregada por aqueles autores. Possivelmente o fato de terem sido utilizados uréia e óleo na dieta dos animais estudados por Ribeiro et al. (2011) proporcionou benefícios ao desempenho e conversão alimentar dos animais. Assim, mesmo com CMS de $4,11 \%$ em relação ao $\mathrm{PC}$, valor este inferior ao obtido no presente trabalho (4,63\% do PC), a CA foi próxima à do presente estudo. O GPD médio encontrado por estes autores foi de $0,287 \mathrm{~kg}$.

Entretanto, Alves et al. (2003) encontraram CA variando de 7 a 10 para animais Santa Inês confinados, submetidos a diferentes teores de energia, com dietas a base de feno de tifton, farelo de soja e milho. Mesmo na dieta mais densa energeticamente (relação V:C de 20,8 : 79,2) a CA foi pior que as obtidas neste trabalho $\mathrm{e}$ àquelas obtidas por Ribeiro et al. (2011), fato este provavelmente resultante de efeitos genéticos, mesmo em se tratando também de animais Santa Inês. Já Turino et al. (2007) encontraram valores de CA próximos a 3,6 , para animais Santa Inês confinados recebendo dietas com alto nível de concentrado (88\%), com GPD de $0,233 \mathrm{~kg}$. Como pode ser observado, os valores de conversão alimentar devem ser analisados com cautela, visto que podem sofrer influência de diversos fatores.

Assim como a conversão alimentar, os dados de consumo, expressos em quilogramas, ou em porcentagem do peso corporal, podem levar a interpretações não muito precisas. Valores de consumo provenientes de dietas com alta densidade energética, ou seja, com baixa concentração de FDN, como as dietas empregadas neste estudo, são melhores expressas em relação ao peso metabólico do que em relação ao peso corporal. Segundo Mertens (1994), dietas menos densas devem ser expressas baseadas no peso corporal, visto que o enchimento do 
Rev. Bras. Saúde Prod. Anim., Salvador, v.16, n.3, p.558-570 jul./set.., 2015 http://www.rbspa.ufba.br ISSN 15199940

rúmen-retículo é o principal fator limitante ao consumo do animal, sendo que a capacidade ruminal está diretamente relacionada com o tamanho corporal dos animais, ou seja, a fatores físicos.

Para dietas nutricionalmente mais densas, a regulação do consumo no geral se dá pelo atendimento à demanda energética, ou seja, por mecanismos fisiológicos. Portanto o uso da unidade de peso metabólico é mais apropriado (MERTENS, 1994).

Em relação ao consumo de nutrientes, foi encontrada diferença $(\mathrm{P}<0,05)$ nos parâmetros de consumo de extrato etéreo (g/dia, \%PC e \%PC ${ }^{0,75}$ ), apresentando um efeito linear positivo, e também nos parâmetros de consumo de FDA (\%PC e $\left.\% \mathrm{PC}^{0,75}\right)$, em que se observou efeito cúbico (Tabela 4).

Tabela 4. Consumo dos nutrientes por cordeiros confinados alimentados com diferentes teores de torta de soja em substituição ao farelo de soja na ração

\begin{tabular}{|c|c|c|c|c|c|c|c|c|}
\hline \multirow{2}{*}{ Item } & \multicolumn{5}{|c|}{ Teores de torta de soja $(\%)$} & \multirow{2}{*}{$\mathrm{R}$} & \multirow{2}{*}{$\mathrm{R}^{2}$} & \multirow{2}{*}{$\begin{array}{l}\text { CV } \\
(\%)\end{array}$} \\
\hline & 0 & 25 & 50 & 75 & 100 & & & \\
\hline \multicolumn{9}{|c|}{ Proteína Bruta } \\
\hline $\mathrm{g} / \mathrm{dia}$ & 271,43 & 262,29 & 284,61 & 258,53 & 246,56 & $\tilde{y}=264,77$ & - & 12,16 \\
\hline$\% \mathrm{PC}$ & 0,87 & 0,83 & 0,90 & 0,85 & 0,81 & $\tilde{y}=0,85$ & - & 9,35 \\
\hline $\mathrm{g} / \mathrm{kg} \mathrm{PC} \mathrm{P}^{0,75}$ & 20,55 & 19,74 & 21,27 & 19,93 & 18,95 & $\tilde{y}=20,10$ & - & 9,03 \\
\hline \multicolumn{9}{|c|}{ Extrato Etéreo } \\
\hline $\mathrm{g} / \mathrm{dia}$ & 37,55 & 42,51 & 51,66 & 54,73 & 55,50 & $\mathrm{~L}^{1}$ & 0,61 & 11,36 \\
\hline$\% \mathrm{PC}$ & 0,12 & 0,13 & 0,16 & 0,17 & 0,18 & $\mathrm{~L}^{2}$ & 0,77 & 8,12 \\
\hline $\mathrm{g} / \mathrm{kg} \mathrm{PC} \mathrm{P}^{0,75}$ & 2,84 & 3,20 & 3,86 & 4,22 & 4,27 & $\mathrm{~L}^{3}$ & 0,80 & 7,80 \\
\hline \multicolumn{9}{|c|}{ Fibra em detergente neutro } \\
\hline g/dia & 481,29 & 454,87 & 510,17 & 458,98 & 428,19 & $\tilde{y}=467,11$ & - & 12,77 \\
\hline$\% \mathrm{PC}$ & 1,54 & 1,45 & 1,61 & 1,51 & 1,40 & $\tilde{y}=1,50$ & - & 9,35 \\
\hline $\mathrm{g} / \mathrm{kg} \mathrm{PC} \mathrm{P}^{0,75}$ & 36,42 & 34,23 & 38,09 & 35,40 & 32,89 & $\tilde{y}=35,45$ & - & 9,22 \\
\hline \multicolumn{9}{|c|}{ Fibra em detergente ácido } \\
\hline $\mathrm{g} / \mathrm{dia}$ & 196,98 & 176,09 & 209,61 & 183,92 & 163,89 & $\tilde{y}=186,44$ & - & 13,88 \\
\hline$\% \mathrm{PC}$ & 0,63 & 0,56 & 0,66 & 0,61 & 0,53 & $\mathrm{C}^{4}$ & 0,70 & 10,14 \\
\hline $\mathrm{g} / \mathrm{kg} \mathrm{PC} \mathrm{P}^{0,75}$ & 14,90 & 13,25 & 15,64 & 14,19 & 12,57 & $C^{5}$ & 0,69 & 10,16 \\
\hline \multicolumn{9}{|c|}{ Nutrientes digestíveis totais } \\
\hline $\mathrm{g} / \mathrm{dia}$ & 1064,17 & 1041,71 & 1108,36 & 1016,15 & 952,36 & $\tilde{y}=1036,37$ & - & 12,40 \\
\hline$\% \mathrm{PC}$ & 3,41 & 3,31 & 3,49 & 3,34 & 3,11 & $\tilde{y}=3,33$ & - & 9,44 \\
\hline $\mathrm{g} / \mathrm{kg} \mathrm{PC} \mathrm{PC}^{0,75}$ & 80,55 & 78,41 & 82,80 & 78,36 & 73,19 & $\tilde{y}=78,67$ & - & 9,18 \\
\hline
\end{tabular}

$\% \mathrm{PC}=$ porcentagem do peso corporal, $\mathrm{g} / \mathrm{kg} \mathrm{PC}^{0,75}=$ gramas por quilograma de peso metabólico, $\mathrm{CV}=$ coeficiente de variação, $\mathrm{R}=$ regressão, $\mathrm{R}^{2}=$ coeficiente de determinação, $\mathrm{L}=$ efeito linear, $\mathrm{C}=$ efeito cúbico

${ }^{1} \hat{Y}=38,8424+0,1917 x, \quad{ }^{2} \hat{Y}=0,1229+0,0007 x, \quad{ }^{3} \hat{Y}=2,78+0,026 x, \quad{ }^{4} \hat{Y}=0,62490-0,0039 x+0,0001 x^{2}-$ $0,00000094 x^{3},{ }^{5} \hat{Y}=14,747-0,084 x+0,0027 x^{2}-0,000021 x^{3}$.

Os dados de consumo obtidos são apoiados pelo estudo de digestibilidade in vivo realizado por Moura et al. (2015), utilizando a mesma torta de soja em níveis de substituição iguais. Assim como constatado para a digestibilidade da MS pelos autores, foi observado por eles coeficientes de digestibilidade estatisticamente iguais para todos os 
Rev. Bras. Saúde Prod. Anim., Salvador, v.16, n.3, p.558-570 jul./set.., 2015 http://www.rbspa.ufba.br ISSN 15199940

nutrientes entre as cinco dietas experimentais.

De maneira similar ao presente trabalho, Moura et al. (2015) também encontraram diferenças significativas no consumo de extrato etéreo expresso em $\mathrm{g} / \mathrm{dia}, \% \mathrm{PC}$ e $\% \mathrm{PC}^{0,75}$. O teor de extrato etéreo encontrado na torta de soja no presente estudo foi de $74,13 \mathrm{~g} / \mathrm{Kg} \mathrm{MS}$, o que resultou no aumento linear do consumo de extrato etéreo de acordo com o aumento da participação da torta de soja na dieta, tanto em $\mathrm{g} / \mathrm{dia}$, quanto em relação ao peso corporal e metabólico, uma vez que os animais não apresentaram desempenho e consumo de MS estatisticamente diferentes.

Assim, mesmo com o aumento no consumo de extrato etéreo, não houve prejuízos na digestibilidade e consumo da matéria seca, visto que o CMS e o desempenho dos animais foram semelhantes entre as dietas, e como apresentado por Moura et al. (2015), não foi observado decréscimo na digestibilidade com o aumento da participação da torta de soja na dieta. Segundo Palmquist \& Mattos (2011), a suplementação lipídica superior a $5 \%$ da matéria seca pode comprometer $\mathrm{o}$ consumo dos animais, principalmente pela baixa capacidade de ruminantes em oxidar os ácidos graxos. Porém no presente estudo, os teores de extrato etéreo na MS não atingiram o nível crítico de $5 \%$.

Como as dietas foram isoprotéicas, não foram encontradas diferenças $(\mathrm{P}>0,05)$ nos parâmetros de consumo de proteína bruta, e os animais apresentaram consumo médio de 264,77g/dia. Cruzando os dados do NRC (2007), que considera o CMS de aproximadamente $3 \%$ do $\mathrm{PC}$, com os dados do presente estudo, em que se obteve CMS de $4,63 \%$ do PC, o consumo de PB (g) esperado era de 209g. Este maior consumo obtido em relação ao estipulado pelo NRC (2007), para garantir $250 \mathrm{~g}$ de GPD, pode ter contribuído para o maior ganho de peso encontrado no presente trabalho.

Uma maior disponibilidade de nitrogênio para a microbiota ruminal tende a favorecer o CMS, causado pelo favorecimento do crescimento da população microbiana, aumentando a taxa de degradação (ORTIZ et al., 2005), e este fato pode ter contribuído com o satisfatório consumo de matéria seca $(1,44 \mathrm{~kg} \mathrm{CMS} /$ dia) e consequentemente com o ganho de peso superior ao esperado, obtidos neste trabalho.

Os valores de consumo de FDN estão dentro do intervalo de $0,8-2,2 \%$ do PC, recomendados por Van Soest (1994), sendo semelhantes entre os diferentes teores de torta de soja estudados $(\mathrm{P}>0,05)$.

Apesar das dietas possuírem teor de FDA similares, observou-se efeito cúbico $(\mathrm{P}<0,05)$ para as variáveis de consumo de FDA em relação ao peso corporal e peso metabólico. Não foi observada diferença no consumo de FDA em g/dia. Provavelmente a diferença se explica pela seletividade dos alimentos pelos animais, o que resultou em sobras desuniformes entre os tratamentos, influenciando nos cálculos de consumo (VAN SOEST, 1994).

Também não foram encontradas diferenças $(\mathrm{P}>0,05)$ no consumo de NDT, mesmo na dieta com $100 \%$ de substituição do farelo de soja pela torta de soja.

Os diferentes teores de torta de soja não influenciaram $(\mathrm{P}>0,05)$ nos parâmetros do comportamento ingestivo dos animais. Os tempos médios das dietas, para as atividades de ócio (TOT), ruminação (TRT) e ingestão de alimentos (TIA), foram de respectivamente 789,29 425,85 e 194,50 minutos (Tabela 5). 
Rev. Bras. Saúde Prod. Anim., Salvador, v.16, n.3, p.558-570 jul./set.., 2015 http://www.rbspa.ufba.br ISSN 15199940

Quanto maior a participação de volumosos na dieta e maior porcentagem de fibra efetiva, espera-se um maior tempo de ingestão de alimentos e ruminação, refletindo em um menor tempo de ócio. Ribeiro et al. (2011) obtiveram valores de tempo de ruminação e ingestão de: 454 e 263 minutos, respectivamente, sendo que neste trabalho, houve maior participação de volumoso na ração completa (relação $\mathrm{V}: \mathrm{C}$ de 47:53) do que no presente estudo.

Segundo Salla et al. (2003) e Silva et al. (2011), além dos teores de FDN, teores mais elevados de extrato etéreo na ração podem afetar a ruminação dos animais, principalmente pela redução da taxa de degradação da fibra, fato este que não foi observado no presente estudo, visto que o comportamento ingestivo e o consumo dos animais foi similar, assim como seus desempenhos. Esta afirmativa pode ser reforçada com base nos dados de digestibilidade de Moura et al. (2015), os quais foram similares para todos os níveis de substituição do farelo de soja pela torta de soja.

Tabela 5. Parâmetros do comportamento ingestivo e de ruminação de cordeiros alimentados com diferentes teores de torta de soja em substituição ao farelo de soja na ração

\begin{tabular}{|c|c|c|c|c|c|c|c|}
\hline \multirow{2}{*}{ Variável } & \multicolumn{5}{|c|}{ Teores de torta de soja (\%) } & \multirow{2}{*}{$\mathrm{R}$} & \multirow{2}{*}{$\begin{array}{l}\mathrm{CV} \\
(\%)\end{array}$} \\
\hline & 0 & 25 & 50 & 75 & 100 & & \\
\hline TRT (min/dia) & 413,4 & 421,8 & 443,4 & 426,6 & 423,0 & $\tilde{y}=425,85$ & 13,35 \\
\hline TIA (min/dia) & 190,2 & 168,0 & 188,4 & 183,6 & 238,2 & $\tilde{y}=194,50$ & 29,58 \\
\hline TMT (min/dia) & 603,6 & 589,8 & 631,8 & 610,2 & 661,2 & $\tilde{y}=620,35$ & 11,97 \\
\hline TOT (min/dia) & 823,2 & 823,8 & 768,6 & 801,6 & 735,0 & $\tilde{y}=789,29$ & 11,55 \\
\hline
\end{tabular}

$\mathrm{CV}=$ coeficiente de variação, $\mathrm{R}=$ regressão, TRT $=$ tempo de ruminação total, TIA $=$ tempo de ingestão de alimento, TMT = tempo de mastigação total, TOT = tempo em ócio total.

Benson et al. (2001), testando a influência da infusão abomasal de mistura de óleo de girassol com óleo de canola $(50 \%$ cada) em vacas leiteiras, em relação à infusão de água, encontraram redução significativa no consumo de matéria seca, apesar de não terem encontrado diferenças significativas nos tempos despendidos em ruminação, ócio e ingestão. Estes resultados sugerem que a redução no consumo ocorreu devido ao mecanismo de saciedade do animal, controlado pelo atendimento à demanda energética, já que o efeito da presença de altos teores de óleo insaturados no rúmen não tiveram participação naquele estudo e automaticamente não era de se esperar influências no padrão fermentativo e consequentemente no comportamento ingestivo dos animais.

No entanto, Salla et al. (2003), testando diferentes teores de extrato etéreo na dieta $(3,67,5,92,6,29$ e $6,70 \%)$ de vacas leiteiras, não encontraram diferenças em nenhum dos parâmetros do comportamento ingestivo avaliados, mesmo superando os teores de EE recomendados na literatura.

As medidas biométricas pré-abate também não foram influenciadas $(\mathrm{P}>0,05)$ pelos diferentes teores de torta de soja nas dietas (Tabela 6). O escore de condição corporal, segundo Osório \& Osório (2005) é uma medida utilizada para estimar o estado de acabamento do 
Rev. Bras. Saúde Prod. Anim., Salvador, v.16, n.3, p.558-570 jul./set.., 2015 http://www.rbspa.ufba.br

animal, podendo ser também utilizada para a estimativa da relação músculoosso. Segundo a sua classificação (1: muito magro, 2: magro, 3: ligeiramente gordo, 4: gordo a 5: muito gordo) os animais, que apresentaram média geral entre os as diferentes dietas de 3,86 , se encaixam na categoria de ligeiramente gordos a gordos. Seguindo os demais parâmetros de desempenho, não foi encontrado efeito das dietas sobre este índice $(\mathrm{P}>0,05)$.

Diferentemente do escore corporal, altamente correlacionado com a nutrição (ARAÚJO FILHO et al., 2007), as medidas biométricas são no geral pouco influenciadas pelas condições ambientais, estando mais relacionadas ao grupamento genético dos animais e ao peso corporal (KORITIAKI et al., 2012).

Tabela 6. Medidas biométricas pré-abate de cordeiros alimentados com teores crescentes de torta de soja em substituição ao farelo de soja na ração

\begin{tabular}{|c|c|c|c|c|c|c|c|}
\hline \multirow{2}{*}{ Variável } & \multicolumn{5}{|c|}{ Teores de torta de soja (\%) } & \multirow{2}{*}{$\mathrm{R}$} & \multirow{2}{*}{$\begin{array}{l}\mathrm{CV} \\
(\%)\end{array}$} \\
\hline & 0 & 25 & 50 & 75 & 100 & & \\
\hline Condição corporal (1 a 5) & 3,79 & 3,90 & 4,00 & 3,87 & 3,75 & $\tilde{y}=3,86$ & 7,87 \\
\hline Comprimento corporal (cm) & 58,33 & 59,60 & 60,83 & 58,67 & 57,00 & $\tilde{y}=58,86$ & 3,87 \\
\hline Perímetro torácico $(\mathrm{cm})$ & 76,67 & 78,40 & 76,17 & 75,33 & 75,83 & $\tilde{y}=76,41$ & 3,99 \\
\hline Altura do dorso $(\mathrm{cm})$ & 69,50 & 66,00 & 68,33 & 70,83 & 68,33 & $\tilde{y}=68,69$ & 3,43 \\
\hline Altura de garupa $(\mathrm{cm})$ & 67,83 & 67,20 & 68,17 & 68,83 & 66,83 & $\tilde{y}=67,79$ & 3,33 \\
\hline Comprimento de perna ( & 30,50 & 30,00 & 30,83 & 31,17 & 30,50 & $\tilde{y}=30,62$ & 3,44 \\
\hline Perímetro perna $(\mathrm{cm})$ & 38,83 & 40,80 & 38,67 & 38,50 & 39,00 & $\tilde{y}=39,31$ & 7,78 \\
\hline Largura da garupa $(\mathrm{cm})$ & 19,67 & 20,60 & 20,33 & 19,33 & 20,83 & $\tilde{y}=20,14$ & 5,74 \\
\hline Largura de peito $(\mathrm{cm})$ & 19,00 & 20,00 & 18,33 & 18,00 & 19,00 & $\tilde{y}=18,83$ & 6,62 \\
\hline
\end{tabular}

$\mathrm{CV}=$ coeficiente de variação, $\mathrm{R}=$ regressão.

Nesse sentido, observa-se que os animais apresentaram médias das medidas de altura de dorso $(68,69 \mathrm{~cm})$ e garupa $(67,79 \mathrm{~cm})$ superiores ao comprimento corporal $(58,86 \mathrm{~cm})$, característica da raça Santa Inês, em que os animais no geral são considerados como altos, como mostrado por Araújo Filho et al. (2007), em que foram comparadas as medidas biométricas de cordeiros Santa Inês, com cordeiros F1 oriundos do cruzamento entra a raça Dorper e Santa Inês e cordeiros da raça Morada Nova, nos quais foram encontrados valores de comprimento corporal de altura de dorso e garupa muito próximos.

No estudo de Araújo Filho et al. (2007) também não foi observado efeito significativo das dietas (baixo e alto níveis energéticos) sobre as medidas. De maneira similar, as demais medidas biométricas avaliadas não foram afetadas $(\mathrm{P}>0,05)$ pelas dietas, uma vez que apoiado pelos resultados supracitados, observa-se que as medidas biométricas são mais influenciados pela genética do que pela nutrição e os animais utilizados no presente estudo eram provenientes do mesmo lote.

Assim, conclui-se que respeitando os limites dos teores de extrato etéreo recomendados, a torta de soja pode substituir totalmente o farelo de soja na alimentação de cordeiros confinados recebendo dietas à base de concentrado, com razão $\mathrm{V}: \mathrm{C}$ de 35:65, sendo uma alternativa interessante principalmente aos pequenos produtores. 
Rev. Bras. Saúde Prod. Anim., Salvador, v.16, n.3, p.558-570 jul./set.., 2015 http://www.rbspa.ufba.br ISSN 15199940

\section{AGRADECIMENTOS}

Os autores agradecem ao Conselho Nacional de Desenvolvimento Científico e Tecnológico $(C N P q)$ e Coordenação de Aperfeiçoamento de Pessoal de Nível Superior (CAPES) pelo suporte financeiro.

\section{REFERÊNCIAS}

ABDALLA, A.L.; SILVA FILHO, J.C.; GODOI, A.R.; CARMO, C.A.; EDUARDO, J.L.P. Utilização de subprodutos da indústria do biodiesel na alimentação de ruminantes. Revista Brasileira de Zootecnia, v.37, p.260268, 2008. Supl. Especial.

ALVES, K.S.; CARVALO, F.F.R.; VÉRAS, A.S.C. Níveis de energia em dietas para ovinos Santa Inês: Desempenho. Revista Brasileira Zootecnia, v.32, n.6, p.1937-1944, 2003.

AMARAL, R.M.; MACEDO, F.A.F.; MACEDO, F.G.; LINO, D.A.; ALCALDE, C.R.; DIAS, F.B.; GUALDA, T.P. Deposição tecidual em cordeiros Santa Inês, $1 / 2$ Dorper-Santa Inês, $1 / 2$ White Dorper-Santa Inês avaliados por ultrassonografia. Revista Brasileira de Saúde e Produção Animal [online], v.12, n.3, p. 658-669, 2011.

ARAÚJO FILHO, J.T.; COSTA, R.G.; FRAGA, A.B.; SOUSA, W.H.; GONZAGA NETO, S.; BATISTA, A.S.M.; CUNHA, M.G.G. Efeito da dieta e genótipo sobre medidas morfométricas e não constituintes de carcaça de cordeiros deslanados terminados em confinamento. Revista Brasileira de Saúde e Produção Animal [online], v.8, n.4, p.394-404, 2007.
BARROS, C.S.; MONTEIRO, A.L.G.; POLI, C.H.E.C.; DITTRITCH, J.R.; CANZIANI, J.R.F.; FERNANDES, M.A.M. Rentabilidade da produção de ovinos de corte em pastagem e em confinamento. Revista Brasileira de Zootecnia, v.38, n.11, p.2270-2279, 2009.

BENSON, J.A.; REYNOLDS, C.K.; HUMPHRIES, D.J.; RUTTER, S.M.; BEEVER, D.E. Effects of abomasal infusion of long chain fatty acids on intake, feeding behavior and milk production in dairy cows. Journal of Dairy Science, v.84, p.1182-1191, 2001.

BRASIL. Ministério de Minas e Energia. Agência Nacional do Petróleo, Gás Natural e Biocombustíveis. Boletim mensal de Biodiesel. Brasília: ANP, 2014. Disponível em: $<$ http://ubrabio.com.br/sites/1800/189 1/PDFs/InformacaoSetor2014/BolBiodies elANPAbr2014.pdf > . Acesso em: 29 maio 2014.

CARVALHO, G.G.P.; PIRES, A.J.V.; SILVA, R.R.; CARVALHO, B.M.A.; SILVA, H.G.O.; CARVALHO, L.M. Aspectos metodológicos do comportamento ingestivo de ovinos alimentados com capim-elefante amonizado e subprodutos agroindustriais. Revista Brasileira de Zootecnia, v.36. n.4, p 1105-1112, 2007.

DETMANN, E.; SOUZA, M.A.; VALADARES FILHO, S.C.; QUEIROZ, A.C.; BERCHIELLI, T.T.; SALIBA, E.O.S.; CABRAL, L.S.; PINA, D.S.; LADEIRA, M.M.; AZEVEDO, J.A.G. Métodos para análise de alimentos. Visconde do Rio Branco: Suprema, 2012. $214 p$. 
Rev. Bras. Saúde Prod. Anim., Salvador, v.16, n.3, p.558-570 jul./set.., 2015 http://www.rbspa.ufba.br ISSN 15199940

KEARL, L.C. Nutrient requirements of ruminant in developing countries.

Logan: Utah State University, 1982. $381 p$.

KORITIAKI, N.A.; RIBEIRO, E.L.A.; SCERBO, D.C.; MIZUBUTI, I.Y.; SILVA, L.D.F.; BARBOSA, M.A.A.F.; SOUSA, C.L.; PAIVA, F.H.P. Fatores que afetam o desempenho de cordeiros Santa Inês puros e cruzados, do nascimento ao desmame. Revista Brasileira de Saúde e Produção Animal [online], v.13, n.1, p.258-270, 2012.

MADRUGA, M.S.; SOUSA, W.H.; ROSALES, M.D.; CUNHA, M.G.G.; RAMOS, J.L.F. Qualidade da carne de cordeiros Santa Inês terminados em diferentes dietas. Revista Brasileira de Zootecnia, v.344, n.1, p.309-315, 2005.

MERTENS, D.R. Regulation of forage intake. In: FAHEY JUNIOR, G.C. (Eds). Forage Quality, evaluation and utilization. Madison: American Society of Agronomy, 1994. p 450-493.

MOTA, C.J.A.; PESTANA, C.F.M. Coprodutos da produção de biodiesel.

Revista Virtual de Química, v.3, n.5, p.416-425, 2011.

MOURA, E.S.; SILVA, L.D.F.; BUMBIERIS JUNIOR, V.H.; RIBEIRO, E.L.A.; PEIXOTO, E.L.T.; MIZUBUTI, I.Y. Use of soybean cake replacing soybean meal in diets of lambs. Semina: Ciências Agrárias, v.36, n.3, p.16431654, 2015.

NATIONAL RESEARCH COUNCIL NRC. Nutrient requirements of sheep. 6.ed. Washington, D.C.: National Academy Press, 1985. 99p.

NATIONAL RESEARCH COUNCIL NRC. Nutrient requirement of small ruminants: sheep, goats, cervids and new world camelids. Washington: National Academy Press, 2007. 384p.
ORTIZ, J.S.; COSTA, C.; GARCIA, C.A. Efeito de diferentes níveis de proteína bruta da ração sobre $o$ desempenho e as características de carcaça de cordeiros terminados em creep feeding. Revista Brasileira de Zootecnia, v.34, n.6, p.2390-2398, 2005.

OSÓRIO, J.C.S.; OSÓRIO, M.T.M. Produção de carne ovina: técnicas de avaliação in vivo e na carcaça. 2.ed. Pelotas: Universitária, 2005.

PAIM, T.P.; CARDOSO, M.T.M.; BORGES, B.O.; GOMES, E.F.; LOUVANDINI, H.; MCMANUS, C. Estudo econômico da produção de cordeiros cruzados confinados abatidos em diferentes pesos. Ciência Animal Brasileira, v.12, n.1, p.48-57, 2011.

PALMQUIST, D.L.; MATTOS, W.R.S. Metabolismo de lipídios. In: PALMQUIST, D.L.; MATTOS, W.R.S. Nutrição de Ruminantes. 2. ed. Jaboticabal: Funep, 2011. p.299-322.

RIBEIRO, E.L.A.; MIZUBUTI, I.Y.; SILVA, L.D.F.; PAIVA, F.H.P.; SOUSA, C.L.; CASTRO, F.A.B. Desempenho, comportamento ingestivo e características de carcaça de cordeiros confinados submetidos a diferentes frequências de alimentação. Revista Brasileira de Zootecnia, v.40, n.4, p.892-898, 2011.

SALLA, L.E.; FISCHER, V.; FERREIRA, E.X. Comportamento ingestivo de vacas Jersey alimentadas com dietas contendo diferentes fontes de gordur anos primeiros 100 dias de lactação. Revista Brasileira de Zootecnia, v.32, n.3, p.683-689, 2003. 
Rev. Bras. Saúde Prod. Anim., Salvador, v.16, n.3, p.558-570 jul./set.., 2015 http://www.rbspa.ufba.br ISSN 15199940

SANTOS, V.C.; EZEQUIEL, J.M.B.; MORGADO, E.S.; HOMEM JUNIOR, A.C.; FÁVARO, V.L.; D'ÁUREA, A.P.; SOUZA, S.F.; BARBOSA, J.C.

Influência de subprodutos de oleaginosas sobre parâmetros ruminais e a degradação da matéria seca e da proteína bruta.

Arquivos Brasileiros de Medicina Veterinária e Zootecnia, v.64, n.5, p.1284-1291, 2012.

SANTOS, V.C.; EZEQUIEL, J.M.B.; MORGADO, E.S.; FÁVARO, V.R.; D'AUREA, A.P.; SOUSA JUNIOR, S.C. Desempenho e digestibilidade de componentes nutritivos de dietas contendo subprodutos de oleaginosas na alimentação de cordeiros. Semina:

Ciências Agrárias, v.35, n.3, p.15771586, 2014.

STATISTICAL ANALYSIS SYSTEM SAS. System for Microsoft Windows: release 8.2. Cary: 2001.

SILVA, D.J.; QUEIROZ, A.C. Análise de alimentos: métodos químicos e biológicos. 3.ed. Viçosa: Universidade Federal de Viçosa, 2002. 235p.

SILVA, V.L.; ROGÉRIO, M.C.P.; ALVES, A.A.; BOMFIM, M.A.D.; LANDIM, A.V.; LEITE, E.R.; COSTA, H.H.A.; FREIRE, A.P.A.

Comportamento ingestivo de cordeiros alimentados com dietas contendo a inclusão de farelo de castanha de caju. Revista da FZVA, v.18, n.1, p.165-181, 2011.

SIQUEIRA, E.R.; ROÇA, R. Q.; FERNANDES, S.; UEMI, A.

Características sensoriais da carne de cordeiros das raças Hampshire Down, Santa Inês e mestiços Bergamácia $\mathrm{x}$ Corriedale, abatidos com quatro distintos pesos. Revista Brasileira de Zootecnia, v.31, n.3, p.1269-1272, 2002.
TURINO, V.F.; SUSIN, I.; PIRES, A.V. MORAIS, J.B.; OLIVEIRA JÚNIOR, R.C. Casca de soja na alimentação de cordeiros confinados: desempenho e características da carcaça. Ciência Animal Brasileira, v.8, n.3, p.495-503, 2007.

VAN SOEST, P.J. Nutritional ecology of the ruminant. 2.ed. Ithaca, NY: Cornell University, 1994. 476p.

YÁÑEZ, E.A.; RESENDE, K.T.; FERREIRA, A.C.D.; MEDEIROS, A.N.; SILVA SOBRINHO, A.G.; PEREIRA FILHO, J.M.; TEIXEIRA, I.A.M.A.; ARTONI, S.M.B. Utilização de medidas biométricas para predizer características de carcaça de cabritos Saanen. Revista Brasileira de Zootecnia, v.33, n.6, p.1564-1572. 2004.

ZUNDT, M.; MACEDO, F.A.F.; ASTOLPHI, J.L.L.; MEXIA, A.A.; SAKAGUTI, E.S. Desempenho e características de carcaça de cordeiros Santa Inês confinados, filhos de ovelhas submetidas à suplementação alimentar durante a gestação. Revista Brasileira de Zootecnia, v.35, n.3, p.928-935, 2006.

Data de recebimento: 02/06/2014

Data de aprovação: 24/08/2015 